\title{
Concept Development Status of Rural Preschoolers
}

\author{
Anju Manocha ${ }^{1}$ and Darshan Narang ${ }^{2}$ \\ 1. Department of HDFS, COHS, CCSHAU, Hisar125 004, Haryana, India \\ 2. Department of Human Development, University of Rajasthan, Jaipur, Rajasthan, India
}

KEYWORDS Concepts. Applications. Performance. Rural Area. Children

\begin{abstract}
The present investigation was carried out in rural areas of Hisar district of Haryana state. To assess the concept development status of rural children, baseline survey was conducted on 240 children of 3-5 years using Boehm Test of Basic Concepts - R (1984). For further in-depth study of children's conceptual development, half of the sample i.e. 120 children were continued with based on their relatively low conceptual scores. These 120 children were again divided into experimental and control group. So 60 children comprised of experimental group and rest 60 children were a part of control group. The results revealed that about half of children fell in average category in their performance. Further analysis of data revealed that 90 percent of experimental and control group children had clarity to 8 and 9 concepts in general. Half of the children could adequately answer 37 concepts in experimental and 39 concepts in control group out of a total of 50 concepts on Form ' $\mathrm{C}$ '. With regard to children's performance on 'Application', half of the children could perform 14-17 concepts out of 25 concepts.
\end{abstract}

Concepts are regarded as the fabric of mental life; they serve to carve up the person's world into functional units. To define 'concept', however, is difficult indeed; it is easier to describe and discuss various concepts than to formulate a definition. A dictionary meaning of concept is "an idea of some things formed by mentally combining all of its characteristics and particulars."

A concept is the basic unit of all types of learning. Human beings from the infancy to old age learn new concepts and use old concept in new situations of their daily life. Individuals differ in their level of concept formation on the basis of their age, intelligence and experience. A child of four years may have a different concept of plant than a teacher of biology. The word concept is used to designate both mental constructs of individuals and also identifiable public entities that comprise part of the substance of the various disciplines. We can also define a concept as ordered information about the properties of one or more things or class of things to be differentiated from and also related to other things or classes of things.

Logically, a concept refers to a phenomenon in a given field that is grouped together because of their common characteristics. For example the word square refers to a unique class of objects, which are manifestly distinct from triangles and circles. Kagan (1987) emphasizing the importance of concepts in life writes that concepts are fundamental agents to intellectual work. The theoretical significance of cognitive agents to concepts in psychological theory parallels the seminal role of valence in chemistry; fence in biology or energy in physics.

The process of concept formation emerges from a big, buzzing, blooming, confusion in which the child is born. The child is endowed with certain biological inheritance at the time of his birth. He gets the knowledge of the external world through sense organs, which are the gateways of knowledge. Sensation is the conscious reaction of mind. This is the process through which human beings become aware of things in their immediate environment, which stimulates their sense organs. The building of concepts starts with the process of sensation.

The sense organs often operate independently and separately of one another. Sensations are disorganized, unrelated and meaningless. For example, a person may sense that an object is of a certain size, color, weight and shape. But before these impressions have any meaning, they must be organized, related to one another and compared with previously experienced sensation. The mental process by which this is done is called perception. Sensation and perception operate simultaneously. It is very difficult to have pure sensation of objects. One does not have sense and then perceive, he perceives while senses. The process of interpreting or giving meaning to sensation results in the formation of percepts. A percept is an organization of sensory experiences about a particular object. It is simply an image of the object, which is immediately presented to the senses. It may be stored in the memory and recalled in future to help develop concepts. The 
process of concept formation proceeds from sensation, perception and conception. Flavell (1999) reported that infants developed concepts, which have readily perceptible instances as cat, dog, cow and tree. These are learnt readily than the concepts without perceptible instances as atom and eternity. With an increase in age, children learn through manipulating objectives and seeing them.

\section{METHODOLOGY}

In order to carry out an intensive study, rural area of Hisar district of Haryana state was selected purposively as the locale of study. A list of villages of Block I (Hisar I) and Block II (Hisar II) of Hisar district was procured from Block Development Office. Following a simple random selection, a survey of 10 villages, 5 from each block, was done. Further to meet the sample size, two villages namely Ladwa and Kharar from Hisar I and two villages namely Rawalwas and Neolikalan from Hisar II were selected purposively as they were found to be matching up to the maximum in their base line profile. Ladwa and Rawalwas from Block I and II respectively served as experimental group villages and Kharar and Neolikalan from Block I and II respectively served as control group villages

To assess the present status of children's conceptual development, baseline survey was conducted on 240 children of 3-5 years using Boehm Test of Basic Concepts-R (1984) (BTBC). As per requirement of the study, a sample of 60 children, (that is 30 children of either sex), was drawn from each of the four selected villages accounting for a total of 240 children In respect of all the four villages, a separate list of boys and girls was prepared on the basis of general conceptual scores obtained by them. The conceptual scores of children (boys and girls separately) were further arranged in ascending order. From each of the experimental group village, 15 boys and 15 girls, who obtained lower conceptual scores relatively, were selected for intervention. So, experimental group comprised of 60 children in total, i.e. 30 from each experimental village. Similar procedure was followed for the selection of 60 children of control group making a total of 120 children as subjects.

\section{RESULTS AND DISCUSSION}

This section includes the results, which are taken to assess the existing level of concepts of children in rural areas. To find out the level of conceptual development among preschoolers, their performance on Form ' $C$ ' and 'Applications' of BTBC was recorded. Table 1 portrays the conceptual status of all the 240 children, who served as respondents for the Baseline survey.

Table 1: Percentile ranks of children on BTBC $(\mathrm{N}=\mathbf{2 4 0})$

\begin{tabular}{lccc}
\hline S. & $\begin{array}{c}\text { Percentile } \\
\text { No. }\end{array}$ & \multicolumn{2}{c}{$\begin{array}{c}\text { Components } \\
\text { ofBTBC }\end{array}$} \\
\cline { 3 - 4 } & & $\begin{array}{c}\text { Form 'C' } \\
\text { No. (\%) }\end{array}$ & $\begin{array}{c}\text { 'Applications' } \\
\text { No. (\%) }\end{array}$ \\
\hline 1. & $1-25$ & $114(47.6)$ & $150(62.5)$ \\
2. & $26-50$ & $60(25.0)$ & $46(19.2)$ \\
3. & $51-75$ & $50(20.8)$ & $34(14.2)$ \\
4. & $76-100$ & $16(6.6)$ & $10(4.1)$ \\
\hline
\end{tabular}

To assess the existing level of cognitive concepts of children, raw scores of respondents and percentile ranks according to their performance on Form ' $\mathrm{C}$ ' and 'Applications' were computed. Table 3 shows that maximum number of children i.e. 47.6 per cent fell below the 25 th percentile ranks showing that they surpassed only 25 per cent of the total children and were surpassed by rest 75 per cent of children. Only 6.6 per cent children could reach up to percentile ranks between 76 and 100, indicating that they had surpassed 75 or more children of the group and were surpassed by only 25.0 per cent children. Out of rest of children, 25.0 per cent children achieved percentile ranks between 25 to 50 showing that they surpassed about 26 to 50 per cent children of the group and thus achieved middle ranks. Remaining 20.8 per cent children achieved percentile ranks between 51 to 75 per cent. Thus, the results showed that about 50.0 per cent of the children (45.8\%) achieved middle ranks. While only 6.6 per cent children achieved higher ranks and 47.6 per cent achieved low ranks between 1 to 25 per cent. The results are in consonance with those of Sandhu (2001) who indicated that maximum percentage of children had retarded cognitive performance against norms.

Similarly in 'Applications' of multiple concepts, most of the children i.e. 62.5 per cent had achieved ranks between 1 to 25 followed by 
19.2 per cent in the category of percentile ranks between 26 to 50 and 14.2 per cent between 51 to 75 . Only 4.1 per cent children achieved higher ranks of 76 to 100 . Thus the table shows that the pattern of performance of the children on both the forms was almost similar though the children felt the concepts of 'Applications' more difficult. Bjorklund and Brown (1998) studied cognitive development of children and found that by the end of infancy, if not earlier, children develop some understanding that people see things. They start using vision related words like 'see' correctly as early as 1.5 to 2.0 yrs. of age. They begin to use some simple concepts appropriately by the age of 2.5 to 3.0 years.

The results of present study revealed that in terms of concept development, about half of children fell in average category and the other half in below or above average category in their performance on Form ' $\mathrm{C}$ '. Whereas on 'Applications' more than sixty per cent children fell in below average category. The results are in collaboration with the findings of Rani (2001) who found out that majority of children fall in dull normal category in terms of general cognitive index.

The study by Kaliramna (1999) also supported the above results. She found moderate and low performance of preschoolers on total cognition.

\section{Conceptual Status of Experimental and Control Group Children}

This section includes the results related to the performance of children of Form ' $\mathrm{C}$ ' and 'Applications' of BTBC (To assess the cognitive status of children, Boehm Test of Basic concepts - 1986 (BTBC) was used). It includes the analysis of Pre-testing scores of 120 children, finally selected after Baseline survey and dividing them into two study groups i.e. control and experimental groups. Table 2 and 3 shows the distribution of children according to their Pretesting scores on Form ' $\mathrm{C}$ ' and 'Applications' of BTBC in both the settings.

\section{Concepts of Form ' $C$ '}

Table 2 illustrates the percentage of children of experimental group having clarity on the concepts of Form ' $\mathrm{C}$ ' in descending order. As per the table, first eight concepts were clear to more than 90 per cent children. Concepts of 'Away', 'Through' 'Top', 'First' etc. have been clearly understood by them. Next sixteen concepts were clear to 75 to 90 per cent children. Further look at the data shows that half the children could understand 37 out of total 50 concepts. Rest of the concepts was accurately answered by 25 to 50 per cent children. In general, however, majority of the children had clarity to about half of the concept items of the test. The performance of control group children according to Table 3 reveals that 90 per cent children had clarity of first 9 concepts. Concepts of Always, Top, Starting, Next to, Behind etc. were understood by them. Next thirteen concepts were clearly understood by 75 to 90 per cent. Thirty nine out of total of fifty concepts were clear to half of the children while rest of the ten concepts had clarity to only 25 per cent to 50 per cent children.

\section{Classification of Concepts of Form ' $C$ '}

Table 2 and 3 depict the children's performance of concepts in Form ' $C$ ' in experimental and control group at different levels. All the 50 concepts of Form ' $\mathrm{C}$ ' were categorized into A, $\mathrm{B}$ and $\mathrm{C}$ level based on the percentage of children performing these concepts in both the study groups. There were 24 'A' level concepts in experimental and 21 'A' level concepts in control group. These were the easiest concepts as judged by accurate performance of 75 per cent children. Second or 'B' level concepts are those, which were performed by 50-75 per cent of children. This level included 13 concepts in experimental and 18 concepts in control group. Third and last level or ' $\mathrm{C}$ ' level concepts included remaining 13 concepts in experimental and 11 concepts in control group. 25-50 per cent children performed these in general.

\section{Concept of 'Applications'}

Table 4 represents the percentage of experimental group children having successful operations of the combinations of concepts of 'Applications' form in descending order. The table shows that first six concepts are the ones, which were clearly understood, by 80 per cent of experimental group children and there were four such concepts in control group (Table 5). Next 8 concept (experimental) and 6 concept 
Table 2: Performance of experimental group children on concepts of Form ' $\mathrm{C}$ ' $(\mathrm{N}=60)$

\begin{tabular}{|c|c|c|c|c|c|}
\hline $\begin{array}{l}\text { S. } \\
\text { No. }\end{array}$ & Concept & $\begin{array}{c}\text { Frequency } \\
\%\end{array}$ & $\begin{array}{c}\text { S. } \\
\text { No. }\end{array}$ & Concept & $\begin{array}{c}\text { Frequency } \\
\%\end{array}$ \\
\hline \multicolumn{6}{|c|}{ 'A' Level Concepts } \\
\hline 1 & Top & $59(98.3)$ & 26 & Seperated & 43 (71.6) \\
\hline 2 & Away & $58(96.6)$ & 27 & Left & 43 (71.6) \\
\hline 3 & Through & 58 (96.6) & 28 & Forward & $42(70.0)$ \\
\hline 4 & Several & $57(95.0)$ & 29 & Farthest & $41(68.3)$ \\
\hline 5 & First & $56(93.3)$ & 30 & Before & $39(65.0)$ \\
\hline 6 & Behind & $56(93.3)$ & 31 & Corner & $38(63.3)$ \\
\hline 7 & Always & $56(93.3)$ & 32 & \multicolumn{2}{|c|}{ Some,not many $37(61.6)$} \\
\hline 8 & Most & $54(90.0)$ & 33 & Right & $35(58.3)$ \\
\hline 9 & Over & $53(88.3)$ & 34 & Between & $35(58.3)$ \\
\hline 10 & Beginning & $53(88.3)$ & 35 & Row & $33(55.0)$ \\
\hline 11 & Front & $52(86.6)$ & 36 & Center & $32(53.3)$ \\
\hline 12 & Side & $52(86.6)$ & 37 & Alike & $31(51.6)$ \\
\hline 13 & End & $51(85.0)$ & \multicolumn{3}{|c|}{ 'C' Level Concepts } \\
\hline 14 & Next to & $51(85.0)$ & 38 & Narrowest & $29(48.3)$ \\
\hline 15 & Part & $51(85.0)$ & 39 & Every & $27(45.0)$ \\
\hline 16 & After & $50(83.3)$ & 40 & Different & $26(43.3)$ \\
\hline 17 & Whole & 49 (81.6) & 41 & Match & $25(41.6)$ \\
\hline 18 & Bottom & 49 (81.6) & 42 & Fewest & $22(36.6)$ \\
\hline 19 & Half & $48(80.0)$ & 43 & As many & $22(36.6)$ \\
\hline 20 & Widest & $48(80.0)$ & 44 & Medium size & $21(35.0)$ \\
\hline 21 & Starting & $47(78.3)$ & 45 & Skip & $20(33.3)$ \\
\hline 22 & Few & $46(76.6)$ & 46 & Third & 19 (31.6) \\
\hline 23 & Last & $45(75.0)$ & 47 & Pair & 19 (31.6) \\
\hline & & $45(75.0)$ & 48 & Second & $17(28.3)$ \\
\hline \multicolumn{3}{|c|}{ ' $B$ ' Level Concepts } & 49 & Other & $16(26.6)$ \\
\hline 25 & Above & $44(73.3)$ & 50 & Never & $15(25.0)$ \\
\hline
\end{tabular}

(control) combinations are those, which have clarity to about $60-80$ per cent children. Further 5 and 6 concepts; respectively have clarity to about 45 per cent children in experimental and control group settings. Rest of the 7 and 10 concepts of 'Applications' form was clearly understood only by $20-40$ per cent or even less than that of children in experimental and control group respectively. Snow and Strope (1991) in a study examined the development of mental rotation matching skills among six to eleven years old children. No sex differences were found but there was an effect for age with older children performing significantly higher. Younger children performed poorly on matching skills than older children

\section{Classification of concepts of 'Applications'}

Table 4 and 5 represent the multiple concepts of 'Applications' form as divided in three levels on the basis of proportion of children performing the concepts. First level of concepts i.e. 'A' level include eight and six concepts that received accurate responses by more than 75 per cent of
Table 3: Performance of control group children on concepts of Form ' $\mathrm{C}$ ' $(\mathrm{N}=\mathbf{6 0})$

\begin{tabular}{|c|c|c|c|c|c|}
\hline $\begin{array}{l}S . \\
\text { No. }\end{array}$ & Concept & $\begin{array}{c}\text { Frequency } \\
\%\end{array}$ & $\begin{array}{c}S . \\
\text { No. }\end{array}$ & Concept & $\begin{array}{c}\text { Frequency } \\
\%\end{array}$ \\
\hline \multicolumn{6}{|c|}{ 'A' Level Concepts } \\
\hline 1 & Always & $59(98.3)$ & 26 & Side & $39(65.0)$ \\
\hline 2 & Top & $59(98.3)$ & 27 & Part & $38(63.3)$ \\
\hline 3 & Starting & 58 (96.6) & 28 & Other & $37(61.6)$ \\
\hline 4 & Next to & $57(95.0)$ & 29 & Away from & $36(60.0)$ \\
\hline 5 & Behind & $56(93.3)$ & 30 & Few & $36(60.0)$ \\
\hline 6 & Through & $56(93.3)$ & 31 & Farthest & $35(58.3)$ \\
\hline 7 & Front & 55 (91.6) & 32 & Separated & $34(56.6)$ \\
\hline 8 & Several & 55 (91.6) & 33 & \multicolumn{2}{|c|}{ Some,not many34 (56.6) } \\
\hline 9 & After & $54(90.0)$ & 34 & Row & $33(55.0)$ \\
\hline 10 & Bottom & $52(86.6)$ & 35 & Different & $33(55.0)$ \\
\hline 11 & Over & $52(86.6)$ & 36 & Left & $32(53.3)$ \\
\hline & Most & $51(85.0)$ & 37 & Corner & $31(51.6)$ \\
\hline 13 & Half & $50(83.3)$ & 38 & Medium size & $30(50.0)$ \\
\hline 14 & Widest & 49 (81.6) & 39 & Right & $30(50.0)$ \\
\hline 15 & Below & $48(80.0)$ & \multicolumn{3}{|c|}{ 'C' Level Concepts } \\
\hline 16 & Before & $48(80.0)$ & 40 & Never & $29(48.3)$ \\
\hline 17 & Between & $47(78.3)$ & 41 & As many & $27(45.0)$ \\
\hline 18 & Center & $46(76.6)$ & 42 & Forward & $27(45.0)$ \\
\hline 19 & Above & 46 (76.6) & 43 & Second & $26(43.3)$ \\
\hline 20 & First & $45(75.0)$ & 44 & Alike & $23(38.3)$ \\
\hline & Last & $45(75.0)$ & 45 & Narrowest & $22(36.6)$ \\
\hline \multicolumn{3}{|c|}{ 'B' Level Concepts } & 46 & Third & $22(36.6)$ \\
\hline 22 & Every & $43(71.6)$ & 47 & Match & $21(35.0)$ \\
\hline 23 & Beginning & $43(71.6)$ & 48 & Skip & $20(33.3)$ \\
\hline 24 & Whole & $42(70.0)$ & 49 & Pair & $19(31.6)$ \\
\hline 25 & End & $40(66.6)$ & 50 & Fewest & $17(28.3)$ \\
\hline
\end{tabular}

experimental and control group children respectively.

'B' level or second category of concepts represents the concepts, which were responded by about $51-75$ per cent children. These included seven concepts in experimental and six in control group. Rest of the eight and ten concepts was performed by $26-50$ per cent experimental and control group children respectively, and was termed as ' $\mathrm{C}$ ' level concepts. These concepts were the difficult ones for the children as these received less accurate responses. Three and four concepts respectively were the most difficult ones as they were performed by 25 per cent or less of experimental and control group children so they are termed as 'D' level concepts. In a study by Batra and Kaur (1993) it was found that the development of basic relational concepts occur in children between 3-4 years of age. It was found that more than 75 per cent of the respondents performed accurately on most of the concept items indicating that children of this age have a general understanding and mastery over these concepts. However, these concepts were found difficult to answer when used in combinations 


\begin{tabular}{|c|c|c|c|}
\hline $\begin{array}{l}\text { S. } \\
\text { No. }\end{array}$ & Concept & Frequency & $\%$ \\
\hline \multicolumn{4}{|c|}{ A Level } \\
\hline 1 & Every and through & 56 & 93.3 \\
\hline 2 & Longest and top & 55 & 91.6 \\
\hline 3 & Across and bottom & 53 & 88.3 \\
\hline 4 & Outside and inside & 53 & 88.3 \\
\hline 5 & All, big, black & 50 & 88.3 \\
\hline 6 & Shortest between tall & 48 & 83.3 \\
\hline 7 & All, wide & 45 & 80.0 \\
\hline \multirow{2}{*}{\multicolumn{4}{|c|}{ B Level }} \\
\hline & & & \\
\hline 9 & Every center & 44 & 75.0 \\
\hline 10 & In order & 42 & 73.3 \\
\hline 11 & Below and above & 41 & 70.0 \\
\hline 12 & Equal number & 39 & 68.3 \\
\hline 13 & Each same as first & 38 & 65.0 \\
\hline 14 & Equal number & 36 & 63.3 \\
\hline 15 & Left end of middle row & 33 & 60.0 \\
\hline \multicolumn{4}{|c|}{ C Level } \\
\hline 16 & In order & 31 & 50.0 \\
\hline 17 & $\begin{array}{l}\text { Farther than one } \\
\text { but not farthest }\end{array}$ & 30 & 50.0 \\
\hline 18 & $\begin{array}{l}\text { More than one and } \\
\text { less than another }\end{array}$ & 30 & 48.3 \\
\hline 19 & All, long, below & 28 & 46.6 \\
\hline 20 & $\begin{array}{l}\text { Taller than one and } \\
\text { shortest than other }\end{array}$ & 26 & 43.3 \\
\hline 21 & Left, first, ship & 23 & 38.3 \\
\hline 22 & In order & 21 & 35.0 \\
\hline 23 & Every one on right side & 18 & 30.0 \\
\hline \multicolumn{4}{|c|}{ D Level } \\
\hline 24 & Right and back & 14 & 23.3 \\
\hline 25 & Second pair & 14 & 23.3 \\
\hline 26 & Right and left & 11 & 18.3 \\
\hline
\end{tabular}

of 2 or 3 . Concepts of match, pair, medium sized etc and alike were found difficult by children.

The results thus revealed that the performance level of both the study groups was almost similar. Ninety percent of experimental and control group children had clarity to eight and nine concepts respectively. Half of the children could adequately answer 37 concepts in experimental and 39 concepts in control group. There were 13 concepts, which were termed difficult by, experimental and 11 by control group children. Thus, it can be concluded that the trend of concept development was similar in both the study groups. Similar trend was observed in the performance of children on 'Applications' of BTBC confirming the simi-larity in concept development level of children in experimental as well as control group. Rani (1993) too corroborated the results of present investigation while assessing basic concepts among preschool
Table 5: Performance of control group children on concepts of 'Applications'.

\begin{tabular}{|c|c|c|c|}
\hline $\begin{array}{l}S . \\
\text { No. }\end{array}$ & Concept & Frequency & $\%$ \\
\hline \multicolumn{4}{|c|}{ A Level } \\
\hline 1 & Top and longest & 55 & 91.6 \\
\hline 2 & All, big, black & 52 & 86.6 \\
\hline 3 & Every and through & 50 & 83.3 \\
\hline 4 & Across and bottom & 50 & 83.3 \\
\hline 5 & All, wide & 47 & 78.3 \\
\hline 6 & Large over small & 45 & 75.0 \\
\hline \multicolumn{4}{|c|}{ B Level } \\
\hline 7 & In order & 41 & 68.3 \\
\hline 8 & Equal number & 39 & 65.0 \\
\hline 9 & Every center & 37 & 61.6 \\
\hline 10 & Each same as first & 36 & 60.0 \\
\hline 11 & Outside inside & 34 & 56.6 \\
\hline 12 & Equal number & 32 & 53.3 \\
\hline \multicolumn{4}{|c|}{ C Level } \\
\hline 13 & In order & 30 & 50 \\
\hline 14 & Below and above & 30 & 50.0 \\
\hline 15 & Shortest, between tall & 26 & 43.3 \\
\hline 16 & All, long, below & 26 & 43.3 \\
\hline 17 & Left end of middle row & 25 & 41.6 \\
\hline 18 & Every one on right side & 22 & 36.6 \\
\hline 19 & Right and left & 20 & 33.3 \\
\hline 20 & $\begin{array}{l}\text { More than one and } \\
\text { less than another }\end{array}$ & 19 & 31.6 \\
\hline 21 & Second and pair & 18 & 30.0 \\
\hline 22 & In order & 16 & 26.6 \\
\hline \multicolumn{4}{|c|}{ D Level } \\
\hline 23 & Left, first, ship & 14 & 23.3 \\
\hline 24 & $\begin{array}{l}\text { Taller than one and } \\
\text { shorter than other }\end{array}$ & 12 & 20.0 \\
\hline 25 & Right back & 10 & 16.6 \\
\hline 26 & $\begin{array}{l}\text { Farther than one but } \\
\text { not the farthest }\end{array}$ & 9 & 15.0 \\
\hline
\end{tabular}

children. She concluded that 12 concepts were termed as ' $\mathrm{C}$ ' level and 2 as ' $\mathrm{D}$ ' level concepts by the children. The children could adequately answer rest of the 36 concepts during pretesting.

\section{REFERENCES}

Batra, S. and Kaur, P.: Development of basic concepts in young children. PTA Magazine, 31 (1): 7-9 (1993).

Bjorklund, D.F. and Brown, R.D.: Physical play and cognitive development: Integration activity, cognition and education. Child Development, 69 (3): 604-606 (1998).

Boehm, A.E.: Boehm's Test of Basic Concepts R. The Psychological Corporation, New York (1986).

Flavell, J.H.: Cognitive development : Children's knowledge about the mind. Ann. Rev. Psychol., 50: 21-45 (1999)

Kagan, J.: Introduction. In: J. Ragan and S. Lamb (Eds.): The Emergence of Morality in Young Children. University of Chicago Press, Chicago (1987).

Kaliraman, Ashu: Home-based Intervention Program on Cognition for Parents of Preschoolers (3 to 4 yrs). Ph.D. Thesis, Child Development, CCS HAU, Hisar (1999). 
Rani, S.: Basic Concepts Among Preschool Children. M.Sc. Dissertation, Child Development, I.C. College of Home Science, CCS HAU, Hisar (1993).

Rani, Usha: Impact of Some Environmental Stimulating Packages on Cognitive Development of 4-6 years Old Pre-school Children. Department of Education. Ph.D. Thesis submitted to Kurukshetra University, Kurukshetra
(2001)

Sandhu, S.: Cognition and Language Intervention Program for Two to Three Years Old Children. Ph.D. Thesis, Child Development. CCS HAU, Hisar (2001).

Snow, Jeffry H. and Strope, E.S.: Development of mental rotation abilities with children. Developmental Neuropsychology, 6: 207-214 (1991). 